\title{
STRATEGI BRANDING USAHA KECIL INDUSTRI PEMPEK KELURAHAN 2 ULU DAN 26 ILIR PALEMBANG
}

\author{
Siti Komariah Hildayanti1) , Juhaini Alie ${ }^{2)}$ \\ 1) Program Studi Magister Manajemen Universitas Indo Global Mandiri \\ Jalan Jenderal Sudirman No. 629 Km. 3,5 Palembang Kode pos 30129 \\ Email : hildayanti@uigm.ac.id ${ }^{1}$, Luhaini@uigm.ac.id ${ }^{2}$
}

\begin{abstract}
ABSTRAK
Dewasa ini bisnis kuliner berkembang sangat pesat. Berdasarkan laporan Badan Ekonomi Kreatif (BEKRAF), sub sector bisnis kuliner memberikan kontribusi Rp. 209 trilyun atau sekitar 32.5\% dari Produk Domestik Bruto (PDB) tahun 2016. Sub sektor tersebut potensial untuk dikembangkan. Kota Palembang terkenal akan kuliner 'Pempek'nya. Pempek adalah produk konsumsi yang potensial dan menjadi peluang bisnis yang menjanjikan. Sekarang ini bisnis Pempek menjamur di Kota Palembang . Produk ini diproduksi oleh berbagai tipe usaha mulai dari mikro, kecil, dan menengah (SMEs). Dalam program Iptek bagi Masyarakat (IbM) ini, dipilih mita usaha kecil Pempek Ita dan Pempek Lala. Kedua mitra memiliki potensi strategi merek (brand) untuk dikembangkan. Perhatian mitra terhadap merek sangat kurang, karena itu produk mitra menjadi lambat dikenal masyarakat luas. Tujuan dari program pendampingan ini adalah untuk meningkatkan kesadaran akan merek (brand awareness) dan brand equity kedua mitra. Disamping itu, program ini juga mengaplikasikan strategi pemasaran dengan Point of Sale Material (POSM), desain label dan kemasan. Dengan strategi branding yang tepat, omzet penjualan berhasil meningkat 20 sampai 30 persen per bulannya sehingga meningkatkan hasil keuntungan kedua mitra. Melalui kegiatan ini brand awareness dan brand equity pelaku usaha kecil akan semakin tinggi dan dapat mempertahankan kelangsungan usahanya.
\end{abstract}

Kata kunci: Branding Strategy, Brand Awareness, Brand Equity.

\section{PENDAHULUAN}

Saat ini bisnis kuliner menunjukkan perkembangan yang pesat. Berdasarkan laporan Badan Ekonomi Kreatif (BEKRAF) bahwa sektor kuliner menyumbang Rp. 209 triliun atau sekitar 32,5 \% Produk Domestik Bruto (PDB) pada tahun 2016.

Dalam rangka program Ipteks bagi Masyarakat (IbM) bertindak selaku mitranya adalah UKM Pempek "Lala" dan Pempek "Ita". Kedua mitra memiliki potensi untuk lebih dikembangkan, khususnya Pempek "Lala" yang sudah berdiri sejak tahun 2007.

Dalam merespon perkembangan bisnis modern yang dinamis dan kompetitif, maka perlu melakukan inovasi pasar maupun produknya. Menurut Guru Manajemen, Peter E. Drucker bahwa inovasi adalah sebuah keniscayaan dalam bisnis modern. Selama ini kedua mitra menjalankan usahanya dengan manajemen konvensional. Padahal dalam merespon bisnis modern diperlukan pendekatan baru agar dapat bersaing dengan kompetitor.

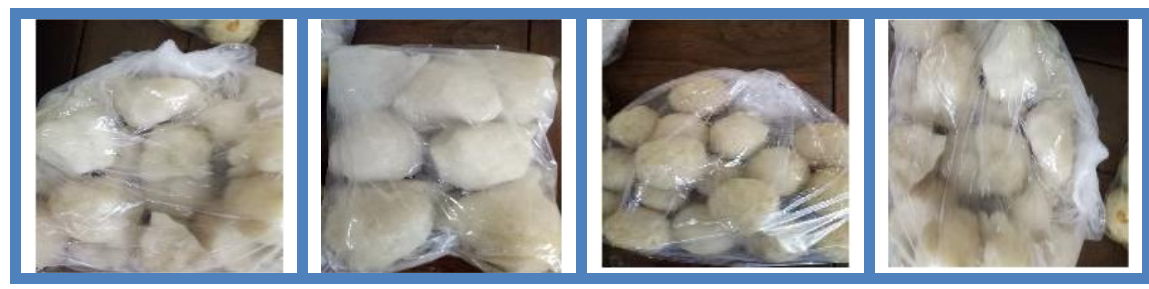

Gambar 1. Bentuk kemasan Konvensional

Salah satu diantaranya dengan menggunakan pemasaran modern, misalnya menggunakan Point of Sale Material (POSM). Definisi POSM adalah sebagai berikut:" A display material to advertise a product where it is being sold e.g posters and dump bins". Pengertian lainnya adalah:" A point of display (POS display) is a specialized form of sales promotion that is found near on or next to a check-out counter (the 
point of sales). POS display can include shelf edging, dummy packs, display packs, display stands, mobiles, poster, and banners".

Terdapat banyak jenis Pempek, antara lain Adaan (Bulat), Lenjer, Kapal Selam, Keriting (Kerupuk), Kulit, dan Telor. Harga jual Pempek bervariasi tergantung pasar dan konsumennya yaitu berkisar antara Rp. 1.000 s.d. Rp. 3.500/ buah. Harga Pempek "Ita" Rp. 1.500/buah dan menggunakan bahan ikan Gabus. Sedangkan Pempek "Lala” harganya Rp. 1.000/buah dengan bahan ikan Kakap.

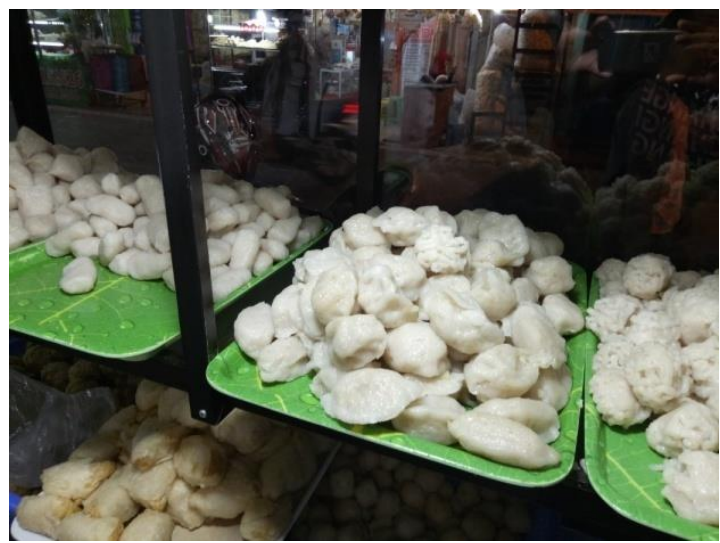

Gambar 2. Beberapa jenis Pempek Produksi kedua Mitra

Produk tersebut adalah makanan khas Palembang yang memiliki nilai keekonomian tinggi. Penjualan lainnya menggunakan sistem paket yang harganya antara Rp. 50.000 sampai dengan Rp. 300.000 /paket. Paket-paket tersebut digolongkan dalam 2 jenis, yaitu paket kecil, sedang, dan besar.

\section{METODE PELAKSANAAN PENGABDIAN}

Metode pelaksanaan yang digunakan adalah: "Action research is either research initiated to solve an immediate problem or a reflective process of progressive problem solving led by individuals working with others in teams or as part of a "community of practice" to improve the way they address issues and solve problems. There are two types of action research: participatory and practical. Denscombe (2010) writes that an action research strategy's purpose is to solve a particular problem and to produce guidelines for best practice" (en.wikipedia.org/wiki/Action_research).

Metode yang diterapkan dalam program IbM ini adalah: 1) Metode "trial and error", yaitu sebuah metode yang lazim digunakan oleh banyak pengusaha Mikro atau UKM; 2) Metode "learning by doing" yaitu melakukan praktek langsung dalam merancang medium POSM, seperti sun screen, desain label dan kemasan.

\section{HASIL DAN PEMBAHASAN}

Selama ini kekuatan merek (brand equity) pempek produksi kedua mitra masih lemah, belum terbentuk atau tercipta di pasar. Meskipun kualitasnya baik dan rasanya enak, tetapi kalah bersaing dengan yang lain. Oleh karena itu, sebagai upaya untuk menciptakan atau membentuk brand equity, maka perlu dilakukan beberapa upaya atau program-program agar produk kedua mitra dikenal di kalangan masyarakat.

Pengertian dari ekuitas merek adalah:" Ekuitas merek memiliki lima dimensi, yaitu kesan kualitas (perceived quality), kesan nilai (perceived value), citra (image), dapat dipercaya (trustworthiness), dan komitmen (commitment)". Menurut Aaker (1997) fungsi dan kekuatan sebuah merek adalah: "Kekuatan merek dapat dilihat dari kuat tidaknya ekuitas merek. Dari sisi perilaku, ekuitas merek penting untuk memberikan diferensiasi yang mampu menciptakan keunggulan kompetitif berdasarkan persaingan non harga".

Oleh karena itu, merek sangat penting untuk sebuah produk atau perusahaan karena memiliki berbagai fungsi dan keuntungan. Bukan sekedar untuk membedakan produknya dengan produk lain atau kompetitor saja. Ironisnya banyak UKM yang mengabaikan sebuah merek.

Membangun kesadaran merek (brand awareness) produk kedua mitra di kalangan konsumen di daerah lokasi penjualan dan sekitarnya. Selama ini kedua produk belum banyak dikenal dan terbatas 
pada konsumen loyal yang menjadi pelanggan. Dampaknya adalah volume penjualan produk tidak meningkat serta marjin keuntungan minim. Oleh karena itu, perlu dibangun kesadaran merek di kalangan calon konsumen maupun pelanggan.

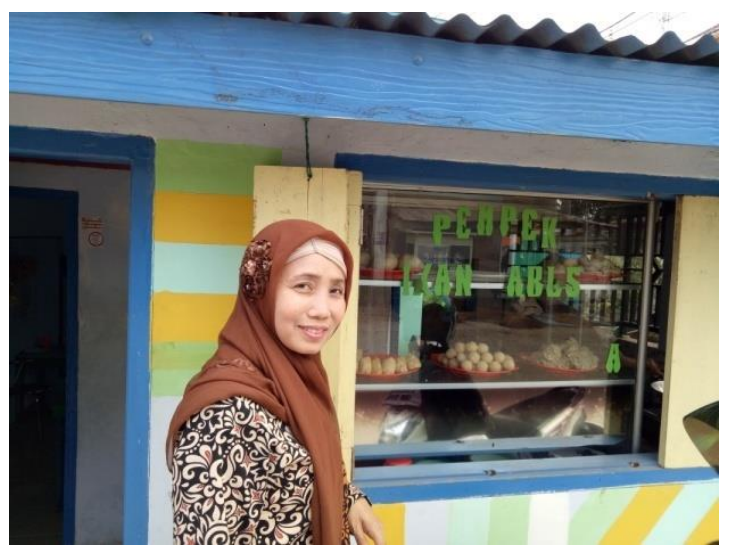

Gambar 4. Tempat penjualan pempek "ita" yang semula tidak memiliki merek

Di dalam rangka membangun kesadaran merek perlu melakukan berbagai upaya, diantaranya melalui pemasangan iklan: "Conventional wisdom dictates that brand awareness (and therefore, brand equity) can be built only through repetitive advertising" (Kohli et al.,2001). Membangun kesadaran merek produk Pempek "Ita" dan Pempek "Lala" sangat penting, khususnya di kalangan calon konsumen. Program membangun kesadaran merek tersebut diharapkan dapat meningkatkan jumlah konsumennya. Program tersebut sekaligus untuk menciptakan kekuatan merek (brand equity) merek "Ita" dan "Lala". Selama ini merek kedua mitra lemah atau dipersepsikan kurang tepat di kalangan calon konsumen. Di bawah ini tampak foto merek di salah satu lokasi mitra, yaitu Pempek "Lala" yang memiliki beberapa jenis huruf dan tidak konsisten. Padahal sebuah merek tidak boleh banyak berubah karena akan memberikan persepsi berbeda kepada pelanggan maupun konsumen.

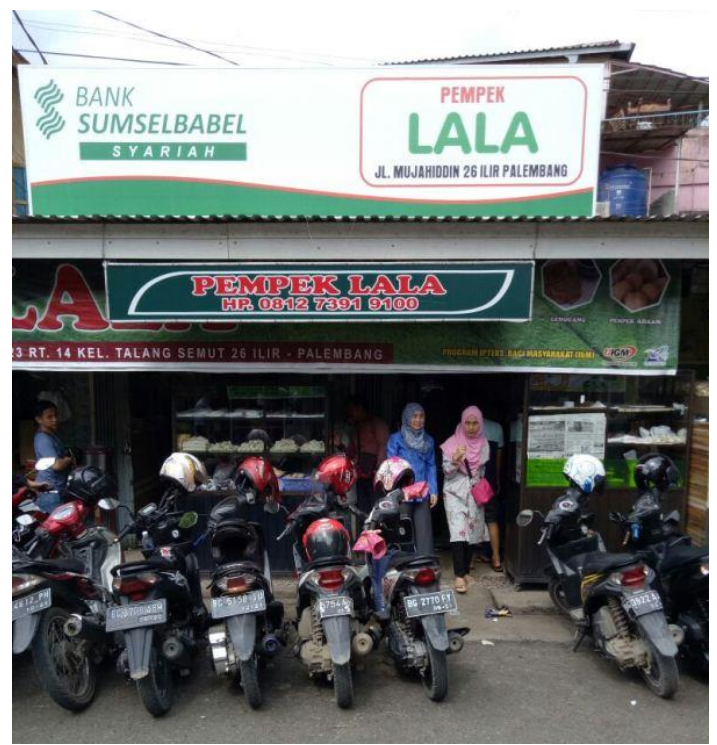

Gambar 5. Lokasi penjualan Pempek "Lala" dengan beberapa jenis huruf pada mereknya.

Perubahan merek dapat berdampak terhadap persepsi pelanggan dan konsumennya. Padahal peran sebuah merek pada sebuah produk sangat penting. Pemahaman pentingnya sebuah merek di kedua mitra masih minim. Mereka beralasan bahwa program-program promosi seperti pemasangan iklan kurang penting, tidak efektif dan memerlukan biaya cukup besar. Sehingga kedua mitra lebih banyak menggunakan pemasaran "dari mulut ke mulut" (Word of Mouth Marketing/WOM) yang dinilai praktis dan tidak memerlukan biaya. Namun dalam konteks bisnis modern, termasuk bisnis Pempek di Kota Palembang yang berkembang pesat dan kompetitif, maka peranan WOM dinilai sudah tidak relevan lagi sehingga dibutuhkan medium pemasaran yang lebih efektif. 


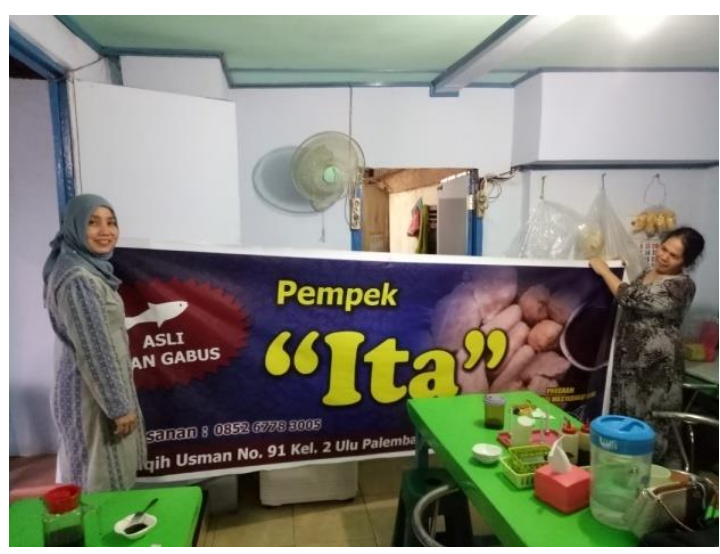

Gambar 6. Spanduk merek Pempek "ita" untuk dipasang di depan tempat penjualan

Dengan demikian, perlu ditingkatkan teknik pemasaran kedua mitra agar lebih baik dan mampu bersaing dengan produk kompetitor. Selama ini teknik pemasaran kedua mitra bersifat sederhana dan pasif yang mengandalkan pelanggan yang loyal dalam melakukan pembelian ulang (repurchase). Namun diperlukan pula pengembangan pasar dengan meningkatkan pembeli-pembeli baru karena sekedar mengandalkan pelanggan yang loyal dapat menyebabkan volume penjualan terbatas.

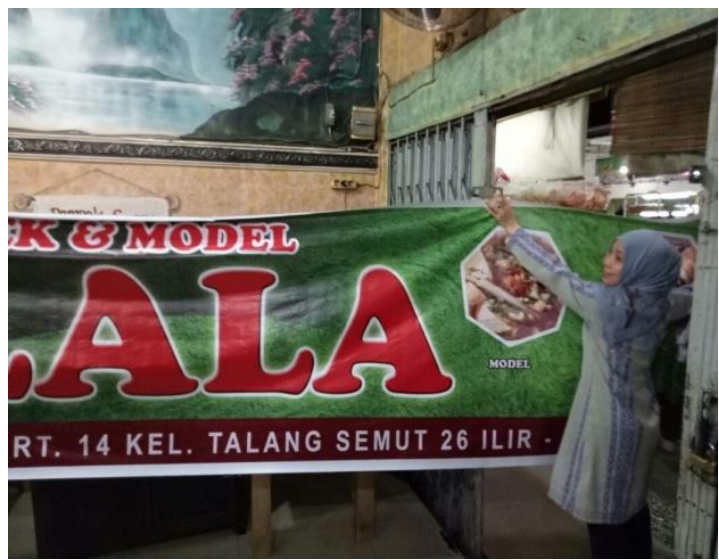

Gambar 7. Sunscreen (spandoek - bahasa Belanda)

Sunscreen (spandoek - bahasa Belanda) adalah salah satu medium POS yang berfungsi sebagai penahan sinar matahari maupun penunjuk lokasi penjualan. Salah satu medium pemasaran adalah kemasan. Meningkatkan pemahaman dan kesadaran mengenai pentingnya peranan desain, baik untuk merancang sebuah label maupun kemasan. Kegagalan sebuah label atau kemasan dapat disebabkan oleh desain yang tidak baik, tidak cocok atau mengabaikan kaidah-kaidah dan unsur-unsur desain seperti warna dan huruf.

\section{KESIMPULAN}

Selama ini kedua mitra menjalankan usaha Pempek dengan manajemen pemasaran sederhana dan pasif, yaitu mengandalkan pembeli atau pelanggan yang loyal maupun calon konsumen baru. Cara pemasaran di atas dinilai sudah tidak relevan dengan perkembangan jaman, khususnya bisnis modern yang dinamis dan kompetitif. Saat ini di Palembang terdapat banyak usaha sejenis yang bersaing mendapatkan konsumen.

Kedua mitra menggunakan teknik pemasaran "Dari Mulut ke Mulut" (Word of Mouth Marketing) yang bersifat sederhana, praktis dan gratis. Dalam kondisi pasar sekarang dan menghadapi persaingan pasar yang ketat, maka medium tradisional tersebut sudah tidak relevan dan tidak efektif.

Kesadaran merek (brand awareness) maupun kekuatan merek (brand equity) kedua mitra belum terbentuk di kalangan masyarakat luas karena kalah bersaing dengan merek-merek besar dan terkenal. Dengan demikian, kedua aspek di atas perlu dibentuk dengan sebuah program yang tepat. 
Kesadaran terhadap fungsi sebuah merek masih minim dan terdapat asumsi bahwa penggunaan merek tidak lebih penting dibandingkan produknya. Padahal keduanya saling terkait di dalam kegiatan pemasaran. Dalam bisnis modern sebuah merek adalah sebuah aset berharga sebuah perusahaan.

Pemahaman mengenai fungsi kemasan masih belum terbentuk karena penggunaan kemasan diasumsikan dapat meningkatkan biaya ekstra atau biaya produksinya. Selama ini kedua mitra menggunakan kemasan bungkus plastik yang sederhana dan murah tetapi kurang menarik calon konsumen. Fungsi sebuah kemasan untuk produk konsumsi sangat penting dan sekaligus dapat menggambarkan kualitas produknya. Produk berkualitas dikemas dengan kemasan yang berkualitas juga. Kualitas sebuah produk tercermin dari kualitas label, kemasan, desain dan sebagainya.

\section{UCAPAN TERIMA KASIH}

Kegiatan pengabdian ini tidak mungkin terwujud tanpa adanya bantuan dari berbagai pihak, baik instansi maupun perorangan. Oleh karena itu, ucapan terima kasih yang sebesar-besarnya kepada:

1. Dirjen Ristek Dikti yang telah maenyelenggarakan program hibah ini.

2. Rektor Universitas IGM Bapak H. Marzuki Alie, S.E., M.M., Ph. D.

3. Ketua LPM2K UIGM Ibu Terttiaavini, S.Kom., M.Kom.

4. Pemilik usaha Pempek Lala Ibu Hj. Nyimas Fadillah.

5. Pemilik usaha Pempek Ita Ibu Yulita.

6. Bapak dan Ibu, Dosen serta mahasiswa yang telah membantu terlaksananya program pengabdian ini.

Semoga menjadi ladang amal dan dapat bermanfaat bagi semua.

\section{DAFTAR PUSTAKA}

Ali, Suparman. 2016. The Effect of Market Segmentation Strategy and Positioning on Customer and Its Impact on Customer Satisfaction on Sundanesse Restaurant in Bandung City. Journal of Marketing and Consumer Research. Vol. 21:1-13.

Belch, George, E., Belch, Michael, A. 2001. Advertising and Promotion. An Integrated Marketing Communication Perspective. Fifth Edition. McGraw-Hill Higher Education. New York.

Chen, Hui-Chu., Green, D., Robert.Brand equity, marketing strategy, and consumer income: A hypermarket study. Journal of Management and Marketing Research.

Fouladivanda, Firoozeh., Pashandi, Amini., Maryam,Hooman,Alireza.,Zahra,Khanmohammadi. The Effect of Brand Equity on Consumer Buying Behavior in Term of FMCG in Iran. Interdisciplinary Journal of Contemporary Research In Business. 2013. 4 (9):945-957.

Kotler, Philip., Amstrong, Gary. 2014. Principles of Marketing. Fithteenth Edition. Pearson Education Limited. England.

Lee, Chai., Goi and Leh, Yew., Chieng., Fayrene. 2011. Dimensions of Customer-Based Brand Equity: A Study on Malaysian Brands. Journal of Marketing Research and Case Studies. 2011:1-10.

Maurya, Kumar., Upendra, Mishra, P. 2012. What is a brand? A Perspective on Brand Meaning. European Journal of Business and Management. 4 (3):122-133.

Pullig, Chris. 2008. What is Brand Equity and What Does the Branding Concept Mean to You? Baylor University. Waco - Texas.

Thomas, Brychan., Miller, Christoper., Murphy, Lyndon. 2011. Innovation and Small Business. Volume 1. Bookboon.com

Whaly, Andrew.2010.StrategicMarketing. First Edition. Bookboon.com

Zhang,Yi. 2015. The Impact of Brand Image on Consumer Behavior: A Literature Review. Open Journal of Business and Management, (3): 58-62. 